\title{
International Journal of Aquatic Research and Education
}

5-1-2014

\section{A Narrative Investigation into Dimensions of Experience at an Outdoor Aquatic Facility: A Pool is More than a Place to Swim}

\author{
Austin R. Anderson \\ University of Southern Indiana, aranderson2@usi.edu \\ William D. Ramos \\ Indiana University \\ Susan E. Middlestadt \\ Indiana University
}

Follow this and additional works at: https://scholarworks.bgsu.edu/ijare

How does access to this work benefit you? Let us know!

\section{Recommended Citation}

Anderson, Austin R.; Ramos, William D.; and Middlestadt, Susan E. (2014) "A Narrative Investigation into Dimensions of Experience at an Outdoor Aquatic Facility: A Pool is More than a Place to Swim," International Journal of Aquatic Research and Education: Vol. 8: No. 2, Article 4. DOI: https://doi.org/10.25035/ijare.08.02.04 Available at: https://scholarworks.bgsu.edu/ijare/vol8/iss2/4

This Research Article is brought to you for free and open access by the Journals at ScholarWorks@BGSU. It has been accepted for inclusion in International Journal of Aquatic Research and Education by an authorized editor of ScholarWorks@BGSU. 


\title{
A Narrative Investigation Into Dimensions of Experience at an Outdoor Aquatic Facility: A Pool is More Than a Place to Swim
}

\author{
Austin R. Anderson \\ University of Southern Indiana
}

\author{
William D. Ramos and Susan E. Middlestadt \\ Indiana University
}

\begin{abstract}
This study used a site-based qualitative research approach to understand aspects of the experience and satisfaction of current users of an outdoor aquatic facility. These aspects described how users identify the setting and perceive positive consequences of partaking in activity at an outdoor aquatic facility. We conducted in-depth interviews with targeted users and analyzed them using systematic constant comparison analysis consistent with tenants of the grounded theory approach. Results indicated that the experience of users gathered around five basic categories of experience: (a) weather and natural environment, (b) physical makeup of the facility, (c) activities engaged in while at the facility, (d) management/administrative issues impacting experience, and (e) community and family. Results also indicated the importance of affective aspects of the facility such as sense of place, family, community, and social interactions. The findings and analyses of these categories can better inform recreational and public health professionals about the needs of various members of their communities in using aquatic facilities; the impact of experiences at aquatic facilities on physical, mental, and social well-being; and overall satisfaction with particular experiences at aquatic facilities.
\end{abstract}

\section{Focus of Study}

To achieve a healthier nation, we need to better understand how to sustain neighborhoods, worksites, and recreational facilities that have the ability to support overall health and well-being. It is widely recognized that activities aimed at improving

Austin R. Anderson is with the Department of Kinesiology and Sport at University of Southern Indiana in Evansville, IN, USA. William D. Ramos is with the Department of Recreation Park, and Tourism at Indiana University in Bloomington, IN, USA. Susan E. Middlestadt is with the Department of Applied Health Science at Indiana University in Bloomington, IN, USA. Address author correspondence to Austin R. Anderson at aranderson2@usi.edu. 
International Journal of Aquatic Research and Education, Vol. 8, No. 2 [2014], Art. 4

public health should not be limited solely to providing education, but should include modifying the settings in which we live, work, and play. The creation of healthy and safe environments is one of four strategic directions included in the first ever National Strategy on Prevention aimed at guiding "our nation in the most effective and achievable means for improving health and well-being" (National Prevention Council, 2011, p. 7). Through the use of a site-based approach focusing on environments with which people interact, healthy choices and activity may be more easily and readily attained.

A site-based approach provides a unique opportunity to address both individual and environmental factors that influence behavior and health. Worksite and school-based wellness programs provide two models of site-based wellness and a natural channel to reach people as many already spend large amounts of time engaged in these settings (United States Department of Agriculture, 2000). Since healthy individuals are more productive, both organizations and individuals benefit from improved health (Goetzel \& Ozminkowski, 2008). Therefore, a community recreation site such as an outdoor aquatic facility could serve as an effective and cost sustainable platform for promoting public health.

An outdoor aquatic facility, which is managed through an effective leisure service delivery system with the main goal of providing fun and enjoyment, also may have the added benefit of encouraging healthy behavior. Connecting health professionals with the public through professionally managed recreation sites, which participants tend to seek out for fun and leisure, may help to aide in the promotion of healthy activity. Stated in alternate terms, through recreational programming there may be supplementary public health behaviors already occurring. Parks can serve a variety of needs beyond physical health (Bedimo-Rung, Mowen, \& Cohen, 2005), and an aquatic facility can fulfill social and mental health needs (Thomson, Kearns, \& Petticrew, 2003). Leisure behavior theories such as the Tinsley and Tinsley attributes, benefits, and causes of leisure experience (1986) and recent works by contemporaries such as Godbey (2008) currently are conceptually connecting leisure, recreation, and health.

These conceptual connections point to the need for public health professionals to collaborate with professionals who understand leisure behavior and the management of recreational facilities and other built environments. The complexity of our physical and social environments accentuates the need for public health professionals to collaborate. To encourage physical activity and active living, an important approach in addressing chronic disease, current ecological models recommend multilevel interventions aimed at a wide range of individual and environmental factors in an effort to achieve population-based outcomes (Sallis, Cervero, Ascher, Henderson, Kraft, \& Kerr, 2006). As a type of intervention, parks and recreational facilities are recognized to provide important benefits to communities and to the individuals who live nearby and use their services (Bedimo-Rung et al., 2005).

While certain types of physical activity have long been recognized for their potential to provide substantial health benefits to large populations, swimming is one activity that should additionally be examined for its ability to provide a range of physical, social, and mental health benefits. Specifically, swimming has been demonstrated to provide moderate or vigorous physical activity important to health (Pescatello, Franklin, Fagard, Farguhar, Kelley, \& Ray, 2004). Swimming is also an extremely popular participatory activity. According to the National Survey on Recreation and the Environment (United Stated Department of Agriculture Agency, 
2002), $60 \%$ of people aged 16 years or older participate in some form of swimming activity. Swimming is ideal for participants who are older, obese, pregnant, or might have difficulty with land-based activities. Swimming improves body fat distribution and insulin in the short term, and, in the longer term, reduces body weight and lipid measures (Cox, Burke, Beilin, \& Puddey, 2010).

It is also important to understand how people perceive aquatic facilities and why they use these facilities within their communities to be able to consider possible adaptations of the built environment and program delivery to optimize public health benefits. Using a three level ecological model, Giles-Corti \& Donovan (2002) found that while access to a supportive physical environment contributes significantly to levels of physical activity, optimization of such activities requires understanding and addressing individual and social environmental factors revolving around use patterns. This study explored this grounded theory analysis by seeking to understand aspects of the experience and satisfaction of current users of an outdoor aquatic facility.

\section{Method}

The strategy of inquiry used in this study employed a narrative-based investigation from targeted users of an outdoor aquatic facility framed in a grounded theory form of analysis. A narrative inquiry method allowed investigation into the lives and experiences of individuals and enabled the individuals to provide informationrich examples of their experiences (Creswell, 2003). In addition, the methodology allowed investigators to critically examine individualized experiences of the participants at the outdoor aquatic facility and for the participants to expand upon any aspect(s) of their experiences which they felt were important. Interview questions posed to participants are presented in Table 1.

\section{Table 1 Sample Interview Question Examples}

- Imagine you are just arriving at the outdoor pool; describe what would be your ideal experience. (Probes: time of day, weather, time of season, surroundings, etc.)

- Tell me a story about a memorable experience you have had while at the outdoor pool.

- Can you describe an experience that you've had involving a water-based environment other than the (this) outdoor pool?

- What is the first thing that comes to your mind when you think about using the outdoor pool?

-What would you do if you could no longer use the outdoor pool?

- If you could add or change anything about the outdoor pool, what would it be?

- [Provide participant with map of facility.] Using this layout of the outdoor pool and surrounding area, take a few minutes and draw anything you could see in regards to physical improvements and/or additions. Any space indicated on the diagram is fair game to include in your drawing. Feel free to take some time to get up and walk around if needed to help make your decisions.

- [Once the subject has returned]: Describe what you've drawn. Why did you include the items? 
International Journal of Aquatic Research and Education, Vol. 8, No. 2 [2014], Art. 4

The grounded theory process analyzes the relationships among categories of information arising from the data collected (Strauss \& Corbin, 1998) to explain a lived experience from the views of participants in the study (Creswell, 2003). The analysis allows important issues to emerge from the participants and their experiences in a particular area of interest (Mills, Bonner, \& Francis, 2006). In this study, the combination of in-depth interview data and constant comparative analysis from within a grounded theory approach allowed the investigators to gather rich, descriptive data from individual participants about their experiences at the outdoor aquatic facility and to categorize and compare the information in an efficient and effective manner.

As the first stage of a three tier multilevel study, we chose qualitative interviews as a baseline to discover meaning and viewpoints from participants that may have been missed had an instrument been developed solely from previous research and the experiences of the investigators. This segment of the overall design was used to inform and direct the development of a semistructured survey for the second phase of inquiry. The final phase of the study used the quantitative survey developed from both Phase I and Phase II.

Five in-depth interviews were completed with current users of an outdoor aquatic facility. Interviewees were specifically selected using purposeful sampling techniques by the research team to identify regular users of the aquatic facility who represented multiple user groups. Participants were contacted by the research team by either phone or e-mail with an explanation of the project and a request for their participation. Interviews took place at the aquatic facility with one member of the research team present, were electronically recorded, and subsequently were transcribed. Participants in the study selected an area on the pool deck to engage in their interview and were provided with a brief introduction about the purpose of the study and their participation as required by the institutional review board. The research team allowed for some extraneous responses by participants in an effort to gain rich data for analysis; however, guiding questions were used where necessary to ensure participants provided targeted responses to the specific interview questions. At the end of the interview, all participants were given a map of the facility and asked to mark on it items or features that they would like to see added and/or changed about the facility. Participants were given approximately 5-10 min to move around the facility and engage in this task before returning to the interview site for discussion. This final exercise served to solidify aspects of the participant experience that were addressed in previous questions and to expand upon additional talking points.

\section{Analysis}

First, multiple members of the research team analyzed interview transcripts using a form of systemic analysis relying on grounded theory procedures (Glaser and Strauss, 1967) with the aim of generating an emergent set of relevant thematic categories. Given the grounded theory approach, data were analyzed using a constant comparison method of data with data, the interpretation (coding) of the data, and categories (Mills et al., 2006). The analysis of the data involved a flexible, selective implementation of content analysis procedures adopted from grounded theory as described subsequently. 
Second, the analysis involved careful and repeated readings of the transcribed interviews by members of the research team to segment each interview into thematic categories in a line-by-line manner. These thematic categories initially were explicit and verbatim in nature, firmly grounding the developed themes in the data. After the initial segmentation process, similar categories were linked to create broader clusters, resulting in the creation of more global of emergent themes categories. Members of the research team then collaborated to analyze the individual emergent themes and create an overarching group of larger thematic elements representing the totality of the data. These categories were related to the experience of outdoor aquatic facility users in an attempt to understand the different experiences that users valued and those in which they sought to engage. The categories represented a generalized interpretation of the data produced through a collaborative analysis process. Within the process, researchers remained mindful of the context of the individualized accounts of experience provided by the key informants who participated in the interview process.

\section{Results}

The experience of the selected users of the outdoor aquatic facility varied widely, but did cluster around several clearly defined thematic categories that emerged from the analyses of the data: (a) weather and natural environment, (b) physical makeup of the facility, (c) activities engaged in while at the facility, (d) management/administrative issues impacting experience, and (e) sense of community and family experiences (see Table 2). While individuals interviewed may have interpreted involvement with these constructs in differing ways, it seemed clear to the investigators that these particular aspects of their experience were important when investigating how the outdoor aquatic facility was used and experienced as a community resource.

\section{Weather and Natural Environment}

Because the facility studied was outdoors, participants regularly mentioned that the weather and natural environment impacted their experience at the aquatic facility. The positive elements tended to draw participants to the facility, while negative ones were responsible for keeping participants from visiting. For example, participants often came to the facility during warm, sunny weather; cooler, rainy weather kept them from visiting the facility.

The outdoor environment of the facility we studied provided particular aquatic activities that attracted participants because there were few natural alternatives. For example, one participant stated, "Well, there really isn't a good option for me in town, you know, the lakes aren't really that appealing for swimming anymore ..." Another participant discussed how the aquatic facility had created natural-appearing surroundings that benefited their experience: “. . . I like the natural environment of this particular pool, because you know having woods next door is really quite special, because there are so many other pools that are in a very concentrated urban setting which I don't want to say is bad; it's just that this is very unique, and I think it is very special." 


\section{Table 2 Findings From Interviews - Thematic Categories of Experience}

\begin{tabular}{|c|c|c|}
\hline Category/Theme & $\begin{array}{l}\text { Factors Contributing } \\
\text { to a Positive Experience }\end{array}$ & $\begin{array}{l}\text { Factors Contributing } \\
\text { to a Negative Experience }\end{array}$ \\
\hline \multirow[t]{2}{*}{$\begin{array}{l}\text { Weather and natural } \\
\text { environment conditions }\end{array}$} & $\begin{array}{l}\text { - Natural environment of the } \\
\text { pool-woods, grass }\end{array}$ & $\begin{array}{l}\text { - Lack of shade/sun } \\
\text { overexposure }\end{array}$ \\
\hline & - Sunny and refreshing & - Extreme weather \\
\hline \multirow[t]{2}{*}{$\begin{array}{l}\text { Physical makeup of the } \\
\text { facility }\end{array}$} & $\begin{array}{l}\text { Welcoming nature of } \\
\text { entrance areas }\end{array}$ & $\begin{array}{l}\text { - Cleanliness and comfort } \\
\text { of rooms and bathing areas }\end{array}$ \\
\hline & & - Lack of artificial shade \\
\hline \multirow[t]{2}{*}{$\begin{array}{l}\text { Activities engaged in } \\
\text { while at the facility }\end{array}$} & $\begin{array}{l}\text { - Wide availability of lap } \\
\text { swimming activities }\end{array}$ & $\begin{array}{l}\text { - Elimination of some } \\
\text { activities due to risk factors }\end{array}$ \\
\hline & $\begin{array}{l}\text { - Pleasant environment } \\
\text { for relaxation Provision } \\
\text { of special events }\end{array}$ & - Crowded conditions \\
\hline \multirow{2}{*}{$\begin{array}{l}\text { Management and } \\
\text { administrative issues } \\
\text { impacting experience }\end{array}$} & Generous hours of operation & $\begin{array}{l}\text { - Lack of information from } \\
\text { management to participants }\end{array}$ \\
\hline & & $\begin{array}{l}\text { - Uncertainty how to provide } \\
\text { feedback }\end{array}$ \\
\hline \multirow[t]{3}{*}{$\begin{array}{l}\text { Sense of community } \\
\text { and family experiences }\end{array}$} & $\begin{array}{l}\text { - Established culture in } \\
\text { existence }\end{array}$ & $\begin{array}{l}\text { Fear of changes to current } \\
\text { culture }\end{array}$ \\
\hline & $\begin{array}{l}\text { - Diversity of participants } \\
\text { (age, ability, family } \\
\text { membership) }\end{array}$ & \\
\hline & $\begin{array}{l}\text { - Ability to spend } \\
\text { recreational/leisure time } \\
\text { with family members }\end{array}$ & \\
\hline
\end{tabular}

Participants also came to this summer season facility due to perceived positive warm weather conditions and the experiences those conditions afforded them. Participants have come to closely associate warm summer weather conditions with this seasonal facility. Participants noted, "In the summertime it's hot, and swimming is a more refreshing way of getting exercise," as well as, "Well . . it's sunshine ... and a refreshing swim." These statements provided evidence that certain anticipated weather conditions positively influence participants' decisions to seek out recreational activities at this aquatic facility.

Participants also noted that the failure to provide certain features at the facility negatively impacted their experience. The lack of these amenities could serve to dissuade participants from coming to the facility. Some comments reflected overexposure to the sun at the facility, noting that insufficient shaded areas were provided. One participant noted, "During lessons you can get a little shade here during the first part of the hour where the sun hits, so maybe more trees around here ..." This sentiment was reinforced by another participant who stated, "We just need more shade ... natural shade would be the absolute best." 
Severe or volatile weather conditions were identified as reasons to avoid the facility or the cause of negative participant experiences. Because this facility was outdoors, a forecast of dangerous weather conditions often persuade participants to forego activity at the facility. For example, one participant stated, "I'm perfectly happy to come over on a cloudy day, even if it's drizzling rain; it doesn't affect my decision to come here... sometimes I don't come because there are thunderstorms ..." Apart from severe storms, oppressive heat also sometimes dissuaded participants from engaging in activity at the aquatic facility; participants noted, "There were some times when it got way too warm," and "The water is only as good as the weather will allow ..." These statements indicated that while exposure to natural elements such as sunshine and warmth normally are positive attributes contributing to a successful experience at the aquatic facility, when heat or weather become more extreme that can also be a detriment.

\section{Physical Makeup of the Facility}

All participants in the study mentioned physical aspects of the facility when describing their experiences. Comments generally revolved around the characteristics of the locker rooms, changing areas, and the availability of artificial shade and shelter. The perceptions of participants regarding a lack of these types of resources often led to less than optimal experiences at the aquatic facility.

The locker room and bathroom facilities were commonly referenced by participants as areas of the facility that could be improved both in terms of furnishings and cleanliness. One participant noted, "They [the locker rooms] could really be enhanced if there were a family changing area ..." and another participant said, "We think they've [facility management] probably never had the changing rooms done over very much. This looks the same since I was going to school here." These comments point to a lack of adequate consideration given to certain types of facilities central to aquatic activities.

Cleanliness and comfort of the locker rooms were noted by other participants. One participant passed on a comment by a family member in saying, "I will point out that the other daughter, who grew up here and grew up going to the pool, was a little bit upset about the cleanliness of the shower area in the women's [area]." Another participant criticized the use of mats in the wet areas of the locker room to help promote cleanliness and prevent slipping in stating, "In the locker rooms, the mats they have on the floor, they are real uncomfortable. I understand that you want something that prevents slips, but that's very uncomfortable to walk on." These critical perceptions didn't prevent participants from engaging in physical activity at the aquatic facility, but the cleanliness and comfort of the facility potentially could lead to decreased usage by certain participant groups, as well as decreased satisfaction of regular users of the facility.

As noted previously in the weather and environment section, the lack of artificial shade was noted by several participants when discussing the physical attributes of the facility. The statements of participants in reference to the lack of available shade were seen as a barrier to protecting themselves from excessive sun exposure and/or oppressive heat. One participant noted, "You don't have like a nice big shady area. There's no real good shady area, and I think it's bothersome ... it might be nice to have a shady area." Another expressed a preference for more 
International Journal of Aquatic Research and Education, Vol. 8, No. 2 [2014], Art. 4

availability of naturally-occurring shade (e.g., from trees and landscaping), but saw difficulties in obtaining that when he observed, "If we can't get natural shade, then some other awnings ... if we could get more tables with umbrellas so that we have more shade." The preference for more shade illustrates the paradoxical balance that must be struck in providing outdoor access to sun while simultaneously providing protection from the health dangers of ultraviolet radiation.

\section{Activities Engaged in While at the Facility}

When questioned about ideal and memorable experiences at the aquatic facility, participant responses uniformly described examples of physical activity in which they had engaged onsite. The types of activities most widely referenced by the participants included general lap swimming, relaxation, special events, and the experiences tied directly to the act of coming to this community aquatic facility. The deep ties between the facility itself and the enjoyable activities in which participants had engaged while at the facility point to the strong positive motivation associated with this type of community recreation.

Participants regularly referenced the availability of general lap swimming, both to the amount of time and space dedicated to it, especially in comparison with other aquatic facilities. One participant stated, "There [are] several lanes for swimming as opposed to some pools that have maybe one or two lanes . . . I think it's nice that this pool favors lap swimming." Another participant drew a comparison with other outdoor aquatic recreation facilities when she noted, "I'd prefer it (the pool) to be more of a place to swim than like a beach." The perception that the facility was widely available for lap swimming activity was reinforced by participants with one saying, "You know, we've got several lanes to swim in all the time (emphasis added)," and another noting, ". . . and then of course you can still do laps anytime." These references to lap swimming availability underlie the important role that this particular activity plays for the recreational experience of participants at this facility, particularly in comparison with other similar community facilities.

Activities related to relaxation also were heavily referenced by participants as reasons to come to this aquatic facility. Some participants associated relaxation to such associated activities as sunbathing and reading when they commented, "I may do a little more reading ..." and "[I] stretch out and do a little bit of sunbathing and reading ..." Other participants characterized relaxation as the way this aquatic facility provided an escape from other daily tasks or distractions. One participant noted, ". . . it's just a real pleasant environment; it gets us away from everything that's at home and all the distractions, and the work to be done and all that sort of thing" and another similarly commented, “. . . they don't see it just as a swimming place, ok, they actually see it as a place to, you know, get away from what is around your house all the time." At least one participant directly related their relaxation time at the aquatic facility to health benefits saying, " . . this pool provides a very good mental health benefit for a lot of people." The provision of a relaxing recreational atmosphere was seen as beneficial to those participants who used it for both escape and leisure.

Special events held at the facility were highlighted by participants as memorable experiences. Many indicated a preference to expand the availability of such events. Special events were perceived as very popular and as a way to offer new 
activities that are not necessarily available to them on a daily basis. One participant responded, "They had a "Bring a Float" day, and what they did was they allowed everybody to bring a float. That was the one time they had it when we came; it was a big hit. I've never seen as many families here as there were on that day." Participants also were aware of events that were held at the facility for particular constituent groups that were important to their experience, "They always have ... you know, 'Back to School' when the students come back; they have an open house." The participant went on to acknowledge the importance and popularity of such unique events, but indicated these events can be expanded for the good of all who use the facility commenting, "I think they ought to have a student night and all that and a band ... why don't they ever do that for families?" Another participant agreed, indicating a preference for a "Community night with some kind of a band or something ...".

The mere experience of coming to the aquatic facility was referenced by most interviewees as a primary motivator for social interaction and participation. There was a sense of connection to the physical space that transcended the activities undertaken at the aquatic facility and that helped to mold recreational and leisure experiences. One participant stated, "The outdoor pool was one of the very first places my wife and I came when we moved here, and we fell in love with it . . . people were really friendly." Other participants pointed to the presence of the aquatic facility itself as the impetus for the recreational activities in which they chose to engage, "We would have to find something else to do, not sure what that would be, nothing related to swimming ..." and one participant underlined the importance of the facility as more than just an aquatic facility, "It's not just a swimming pool where people come in and put in their laps and leave." The importance that participants placed on the social experience of going to the facility indicated that its presence in the community served a vital role in the recreational and leisure choices of these participants. At the same time, it enabled them to engage in healthy activities that they may not otherwise have been inclined or able to do.

\section{Management and Administrative Issues Impacting Experience}

The role of management in the implementation of administrative policies at recreational facilities can serve to significantly impact the participant experience (Driver $\&$ Burns, 1999). How an individual participant experiences the rules put in place by management and administrative policy can serve to determine how satisfied a participant may be with her/his recreational experience. The participants in this study pointed toward two main areas influenced by management that impacted their personal experiences at the aquatic facility: (a) time availability/schedule and (b) perceived lack of information.

Participants who referred to the hours of availability commented that the aquatic facility had long hours that encouraged attendance by a wide variety of participants. One participant stated simply, "The hours are very generous," while another expanded on it by stating, "I am very grateful that the university has generous and flexible hours for people to swim, and I feel fortunate ..." The wide range of available time was perceived as a direct attempt by management to accommodate a variety of personal schedules. This was reinforced by one participant's response 
International Journal of Aquatic Research and Education, Vol. 8, No. 2 [2014], Art. 4

that, “ . . . I'm grateful that we have the opportunity given everybody's different schedules to have lots of chances to swim during the day."

Participants also discussed several issues related to a perceived lack of information regarding rules and regulations associated with the facility. The first issue involved a misunderstanding about the availability of the facility to community members "outside" of the university. One participant stated, "We used to take our kids to the beach first. We didn't know we were allowed to come here." Another, in reference to the surrounding town and community members, said, "I don't think they are aware that they can come (to the pool)." In addition to the lack of information about the availability of the facility to the community at large, one participant indicated a level of frustration with the interpretation of rules and how to provide feedback, saying, "We have suggestions, but we can't implement them; we don't know what the rules are." This sense of frustration about who was allowed to access the facility and how information is exchanged between management and participants could lead to increased levels of dissatisfaction with how the facility is operated. In turn, that frustration can jeopardize attendance and participation at the facility.

\section{Sense of Community}

To participants in this study, the aquatic facility was often seen as much more than just a human-constructed environment where certain activities took place; it was often a focal point in their sense of community and other social interactions. Social and community interactions revolved around the overall atmosphere created at the aquatic facility. Other influencing factors included user perceptions of other groups such as youth and elderly, as well as the desire of participants to be around other people as motivators for coming to the facility.

When participants in the study referred to the social atmosphere created at the aquatic facility, they expressed a desire to protect the sense of community that currently existed. They likewise worried how possible changes to hours and access would negatively affect that sense of community membership. One participant stated, "I would hate to see anything done that would promote a different clientele," and another expressed support for the current community structure at the aquatic facility by saying, "I very much like the culture here as well." When expressing their desire to keep the aquatic facility community close to its current structure, participants pointed to the perceived diversity of the current clientele and the respect that participants have for one another as the main attributes of the aquatic facility community. One member said, "When you look around at lots of people, there's just people who come every day who read and eat lunch; there's people who come here to swim and see friends; I mean, it's just so many fibers and a diverse group of people." Another described the diversity and sense of community by saying, "There seems to be um, I guess, a mutual respect of everybody that swims here." This positive social atmosphere seemed to be an important factor for participants when determining if they would come to the facility for their recreation and leisure time.

Participants also valued the importance for the wide variety of ages and the unique generational interactions that the aquatic facility community provided. When discussing the importance of the facility to youth in the community, one participant observed, "I think it enhances young people and their interest in swimming and diving and the fact that it's (the pool) here is really an important aspect," Another 
supported this statement by noting, "Kids like it, and I think it's a good balance between kids and families and individuals." The interactions between participants of differing ages also provided a unique aspect to participant experiences at the aquatic facility. One participant expressed the facility's unique role in this interaction by saying, "It's one of the places that different generations come together so you have kids swimming, elderly people swimming, blind people swimming, disabled people swimming . . ." while another pointed out a similar experience saying, "(You have) elderly people, middle-age, young people, all ages all using the same facility."

The facility was seen by some of the participants as a primary way in which they were able to socialize with other people with whom they desired to interact. Several participants referenced the social nature of the aquatic facility community by stating, "I enjoy meeting people here every day I'm here ... so there's a social aspect," and, "This is a good place to meet people because we've been here a number of years, you get to know a lot of other pool users." The aquatic facility was seen as a facilitator of social interaction in ways that other facilities might not. One participant stated, "It's the people that I know here that I don't know anywhere else in the community; I've developed a lot of really great friendships." Another reinforced the enjoyment of the highly social nature of the facility by saying, "It's fun just because it's a big gathering of people. There is always something to look at and watch and have fun with."

\section{Family-Related Experiences}

Activities that participants engaged in at the aquatic facility often were associated with personal family interactions. The facility was widely viewed as a place that motivated people to engage in aquatic activity while also being able to interact and spend quality time with one's spouse, children and grandchildren. These close familial interactions served to elevate the physical activities in which the participants were engaged into more meaningful social recreation and leisure experiences.

Several participants recalled important experiences that took place at the aquatic facility between themselves and their spouses. One expressed a sense of surprise and wonder at how a seemingly mundane recreational activity (e.g., visiting a community pool) served to increase the bond and interaction between he and his wife when he commented, “. . . I never would have thought, if you'd have asked me back in the early days, 'Do you think it [going to the pool] would have been like this and lead to something?' I would have said, 'Well, I don't see how . . ., ' but it did. That was great." Another participant pointed to the importance of the aquatic facility as a physical location for bonding with his spouse by noting, "This place, it just became a very important place for both of us . . ." These spousal bonding experiences underlined the social importance of family that community recreational facilities may have along with providing opportunities for individual and family health through physical activity.

Participants also pointed to the importance that interactions at the aquatic facility had for them and their children over extended periods of their lifespan. For one participant, the aquatic facility provided a recreational outlet for his daughter that wasn't available at other facilities. He noted, "My daughter has a disability and loves to swim ... it's been extended for all the years that we've come ... a very 
International Journal of Aquatic Research and Education, Vol. 8, No. 2 [2014], Art. 4

memorable time (was) when the management of the pool looked at our situation and felt that there's no reason that certain things couldn't be accommodated." Another participant saw the importance of the aquatic facility experience in the interactions that others had with their families saying, "... fathers and mothers in the pool with their kids, I mean, I think it's great for parents to bring their kids but I also think it's great to see kids in the pool with their (parents)." The power of the aquatic facility to bring parents and children together around one recreational activity is manifested in the bonds that the participants recalled forming at the aquatic facility.

The bonds formed at the aquatic facility between parents and children over time have extended into the next generation which was evident as participants expressed the importance that the aquatic facility played in their relationship with grandchildren. Even participants who did not directly experience the aquatic facility with their grandchildren observed that the facility did seem to serve an important purpose in this generational exchange, with one responding, "They're people who come here with grandkids, it's just . . . a diverse group of people." Other participants directly expressed the importance of the aquatic facility in their own interactions with their grandchildren specifically. One participant stated, "Some of the most memorable things have been bringing the grandchildren here and seeing them enjoy it," and another said, "It's been a hangout for our family for the last 30 years!"

\section{Discussion}

The statements made by participants in this study associated with their experiences at the aquatic facility clearly fit within five specific thematic categories: weather and natural environment, physical makeup of the facility, activities engaged in while at the facility, management and administrative issues impacting experience, and sense of community and family experiences. The value of the different areas and the impact on participant decisions to come to and engage in activity at the aquatic facility varied across participants, but all participants tied importance to one or more of the emergent thematic categories. By developing a thorough understanding of the ways in which participants engaged in activity at this aquatic facility, and the importance that they placed on the various factors of experience, the investigators could provide information to the facility management to help them better anticipate and react to the needs of various members of the community who rely on this recreational facility as a location for engaging in physical and social activities that positively impacted their health and well-being.

Information derived from our study could inform recreation and aquatic professionals in several very practical ways. Most obvious is the importance of gauging a level of participant satisfaction with current programs and assessing the participant perceptions of how management is able to meet needs and expectations. Our results also indicate that it is important to consider social and affective aspects of the facility such as sense of place, sense of community, family interactions, and social connections. Often times in our experiences, recreational management systems may attend to more concrete aspects of facility operations and may neglect the impact that social and emotional ties possess in creating positive user experiences. Taking the time to purposefully foster and grow these types of connections may aid in developing a stronger positive culture and greater longevity among user groups. 
In addition, responses regarding available (or unavailable) natural elements may indicate that management should consider how to incorporate them when possible to enhance the overall experience. This concept aligns with studies such as the one performed by Hartig, Evans, Jamner, Davis, and Garling (2003) which indicated that even small amounts of natural space within view has the capacity to impact mental and physical wellness.

The researchers plan to use what they learned from this study to construct other research tools that will allow them to investigate other elements of participant experience at aquatic facilities. The thematic categories that emerged from in-depth interviews with participants in this study may become important to our subsequent experiences at other aquatic facilities. Subsequent studies can validate whether these or similar categories emerge as we attempt to generalize and even predict future participant behaviors at other aquatic facilities.

We believe that recreational facility managers and public health professionals alike can benefit from an understanding of participant experiences at community recreational facilities. These diverse recreational facilities may play an important role in the physical, mental and social well-being of our local communities. By gaining a better and deeper understanding of the types of experiences that participants have at these facilities can enable us to advise the relevant decision-makers how to engage in appropriate positive management and promotional activities and avoid inappropriate, negative elements. Participants who are motivated by previous experiences to continue to engage in recreational activities of the types discussed in this paper may exhibit better overall physical, mental, and social health behaviors than those that do not engage in such activities. Additional future research is needed to strengthen our documentation that these aquatic recreational experiences may play critical roles in overall public health and well-being. Future research that employs existing integrative behavior models and theories of leisure, recreation, and physical activity as well as uses grounded theory analysis to critically examine and understand the individual experiences and beliefs of participants at recreational aquatic facilities hold the greatest promise to expand our understanding.

\section{References}

Bedimo-Rung, A.L., Mowen, A., \& Cohen, D. (2005). The significance of parks to physical activity and public health. American Journal of Preventive Medicine, 28(2), 159-168. PubMed doi:10.1016/j.amepre.2004.10.024

Cox, K.L., Burke, V., Beilin, L.J., \& Puddey, I.B. (2010). A comparison of the effects of swimming and walking on body weight, fat distribution, lipids, glucose, and insulin in older women-the Sedentary Women Exercise Adherence Trial 2. Metabolism: Clinical and Experimental, 59(11), 1562-1573. PubMed doi:10.1016/j.metabol.2010.02.001

Creswell, J. (2003). Research Design Qualitative, Quantitative, and Mixed Methods Approaches. Thousand Oaks, CA: Sage Publications.

Driver, B.L., \& Burns, D. (1999). Concepts and uses of the benefits approach to leisure. In E. Jackson, \& E. Burton (Eds.), Leisure Studies: Prospects for the twenty-first century (pp. 349-368). State College, PA: Venture Publishing.

Giles-Corti, B., \& Donovan, R. (2002). Socioeconomic status differences in recreational physical activity levels and real and perceived access to a supportive physical environment. Preventive Medicine, 35, 601-611. PubMed doi:10.1006/pmed.2002.1115 
International Journal of Aquatic Research and Education, Vol. 8, No. 2 [2014], Art. 4

Glaser, B., \& Strauss A. (1967). The Discovery of Grounded Theory. Chicago: Aldine.Godbey, G. (2008). Leisure in Your Life: New Perspectives. State College. PA: Venture Publishing. Goetzel, R.Z., \& Ozminkowski, R. (2008). The health and cost benefits of work site health promotion programs. Annual Review of Public Health, 29, 303-323. PubMed doi:10.1146/annurev.publhealth.29.020907.090930

Hartig, T., Evans, G.W., Jamner, L.D., Davis, D.S., \& Garling, T. (2003). Tracking restoration in natural and urban field settings. Journal of Environmental Psychology, 23, 109-123. doi:10.1016/S0272-4944(02)00109-3

Mills, J., Bonner, A., \& Francis, K. (2006). The development of constructivist grounded theory. International Journal of Qualitative Methods, 5(1), 25-35.

National Prevention Council. (2011). National Prevention Strategy. Washington, D.C.: U.S. Department of Health and Human Services.

Pescatello, L.S., Franklin, B., Fagard, R., Farguhar, W., Kelley, G., \& Ray, C. (2004). American College of Sports Medicine position stand: Exercise and hypertension. Medicine and Science in Sports and Exercise, 36(3), 533-553. PubMed doi:10.1249/01. MSS.0000115224.88514.3A

Sallis, J.F., Cervero, R., Ascher, W., Henderson, K., Kraft, M., \& Kerr, J. (2006). An ecological approach to creating more physically active communities. Annual Review of Public Health, 27, 297-322. PubMed doi:10.1146/annurev.publhealth.27.021405.102100

Strauss, A., \& Corbin, J. (1998). Basics of qualitative research: Techniques and procedures for developing grounded theory (2nd ed.). Thousand Oaks, CA: Sage.

Thomson, H., Kearns, A., \& Petticrew, M. (2003). Assessing the health impact of local amenities: A qualitative study of contrasting experiences of local swimming pool and leisure provision in two areas of Glasgow. Journal of Epidemiology and Community Health, 57, 663-667. PubMed doi:10.1136/jech.57.9.663

Tinsley, H., \& Tinsley, D. (1986). A theory of the attributes, benefits, and causes of leisure experience. Leisure Sciences, 8(1), 1-45. doi:10.1080/01490408609513056

U.S. Department of Health and Human Services. (2010). Healthy People 2020. Washington, D.C.: USDHS. Retrieved from http://www.healthypeople.gov/2020/default.aspx

United Stated Department of Agriculture. (2000). National survey on recreation and the environment. Washington, D.C.: USDA. Retrieved from http://www.srs.fs.usda.gov/ trends/Nsre/nsrerep.html 